\title{
In vitro Transdermal Transport of Domperidone by Compartmental Modeling Approach
}

\author{
Sekar Ayu Pawestri ${ }^{1}$, Akhmad Kharis Nugroho' ${ }^{*}$ and Endang Lukitaningsih ${ }^{2}$
}

1. Department of Pharmaceutics, Faculty of Pharmacy, Universitas Gadjah Mada, Yogyakarta 55281, Indonesia

2. Department of Pharmaceutical Chemistry, Faculty of Pharmacy, Universitas Gadjah Mada, Yogyakarta 55281, Indonesia

\begin{tabular}{l}
\hline Info Article \\
\hline Submitted: $24-08-2020$ \\
Revised: $13-01-2021$ \\
Accepted: $26-02-2021$ \\
*Corresponding author: \\
Akhmad Kharis Nugroho \\
Email: \\
a.k.nugroho@ugm.ac.id
\end{tabular}

\section{ABSTRACT}

Transdermal delivery can be alternatively chosen for domperidone to improve its low oral bioavailability. The development of drugs into transdermal formulation needs information about the transport mechanism of the drug. This study aimed to develop models of domperidone transdermal transport in vitro based on compartmental modeling for understanding the domperidone transport mechanism. Domperidone solution $(0.5 \mathrm{~g} / \mathrm{L}$ in a citric buffer, pH 5) was filled into the donor compartment. A comparative study was also conducted to examine the effect of different $\mathrm{pH}$ on domperidone transdermal transport in $\mathrm{pH} 1(4 \mathrm{~g} / \mathrm{L}$ in $0.1 \mathrm{M} \mathrm{HCl})$. The shed snake-skin and cellophane membrane were pretreated for $1 \mathrm{~h}$ with a chemical enhancer (oleic acid in propylene glycol) and assembled between the donor and the vertical diffusion cell's receptor compartment. The receptor compartment was filled in with phosphate-buffered saline at a $\mathrm{pH}$ of 6.8. The permeation study was performed for $8 \mathrm{~h}$. Samples concentration was assayed by UVspectrophotometry. The cumulative permeation profiles of domperidone were analyzed using WinSAAM. Three and four-compartmental models were proposed with the one lag compartment. The evaluation of the appropriate number of compartments in the transport model was examined based on the visual goodness of fit (GOF) and the corrected Akaike's information criterion (AICc) values. The four-compartmental model with one lag compartment was the best model describing percutaneous domperidone transport either in $\mathrm{pH}$ donor of 5 or $\mathrm{pH} 1$. The model indicates domperidone transport follows into two parallel routes, including a lag compartment.

Keyword: Transdermal, Domperidone, compartmental modeling, WinSAAM

\section{INTRODUCTION}

Domperidone, a dopamine antagonist, is an antiemetic and prokinetic agent with a recommended single dose of $10 \mathrm{mg}$ and a total daily dose of $40 \mathrm{mg}$ (Boyce et al., 2012). The extensive first-pass metabolism in the intestine and liver results in a low domperidone's oral bioavailability (13-17\%). The elimination half-life of domperidone is about 7-9h (Helmy and El Bedaiwy, 2014). An alternative formulation is via a transdermal delivery route. It can avoid the first-pass metabolism in the liver, increasing the bioavailability of drugs. It also has good acceptance for the patient (Sarath et al., 2014). However, the drug must pass the barrier of the skin (i.e., stratum corneum). Chemical enhancers can improve skin penetration of the drug. Oleic acid $(\mathrm{OA})$, one of the chemical enhancers, temporarily disrupts the stratum corneum lipid, increasing the skin's fluidization and diffusivity (Haque and Talukder, 2018). Furthermore, there are reports that $\mathrm{OA}$ in propylene glycol (PG) can synergistically increase drug permeation. This combination has been reported to increase the transdermal transport of thymoquinone, propranolol, and alfuzosin (Haq and MichniakKohn, 2018; Hendriati and Nugroho, 2009; Pattnaik et al., 2011).

There is no report yet about transdermal delivery of domperidone with OA in PG enhancers, as well as the concern on the transdermal domperidone transport mechanism. This 
investigation is essential to study domperidone characteristics while passing across the skin layer. Compartment modeling is a mathematical model representation of parts of the body to assess pharmacological or physiological kinetic characteristics (Khanday etal.,2017). This modeling approach describes transdermal transport as a drug mass transfer process from the donor compartment to the acceptor compartment via the skin as an intermediate compartment (Nugroho et al., 2004). Compartmental modeling has several advantages. First, the parameter of transport can be analyzed directly from the original flux data. Second, the entire observed data can be analyzed without excluding some data points, such as the diffusion lag time method. Compartment modeling also describes the flux as a function of time to predict the steady-state flux, even though the condition has not been achieved (Nugroho et al., 2004).

Several studies have been conducted to describe drug transport based on compartmental modeling. Such an approach has been applied in transdermal iontophoresis in vitro (Nugroho et al., 2004) and in vivo (Nugroho et al., 2005); and in passive transdermal transport in vitro (Nugroho et $a l ., 2014)$. The models can be built in by WinSAAM, free software for the biological system modeling (Stefanovski et al., 2003). This study aimed to describe the transport mechanism of domperidone combined with OA in PG, based on the compartmental modeling approach. As a comparative study, we also studied the influence of extreme $\mathrm{pH}$ (i.e., $\mathrm{pH}$ 1) and enhancer concentrations on the permeation and compartment model of domperidone.

\section{MATERIAL AND METHODS}

Domperidone (Vasudha Pharma Chem Ltd., India), shed-snake skin of Albino Burmese Python species (Yogyakarta, Indonesia), cellophane membrane (Fisher Sci. Co., USA), distilled water, oleic acid, and propylene glycol (Dow Chemical Pacific, Singapore), $\mathrm{Na}_{2} \mathrm{HPO}_{4}$, $\mathrm{KH}_{2} \mathrm{PO}_{4}, \mathrm{KCl}, \mathrm{NaCl}$, and $\mathrm{HCl}$ were of analytical grade (Merck, Germany). The instrument used was UVVis Spectrophotometer (Genesys 10S, USA).

\section{Shed snake-skin pretreatment}

Both the shed snake-skin and cellophane membranes were cut into circular shapes $1.5 \mathrm{~cm}$ in diameter using scissors. They were then hydrated in phosphate-buffer saline (PBS) at a pH of 6.8 for $30 \mathrm{~min}$. The cellophane was used as a supporting membrane for the shed snake-skin. The shed snake-skin was put above the cellophane membrane when assembled between the donor and the diffusion cell's receptor compartment. Oleic acid in various concentrations $(1 \%$ for $\mathrm{pH} 5$ and $1 ; 5 ; 10 \%$ for $\mathrm{pH} 1$ ) in propylene glycol were prepared. A composition of $3 \mathrm{~mL}$ of oleic acid in propylene glycol was filled into the diffusion cell's donor compartment. The receptor compartment was filled in with PBS at a pH of 6.8. The skin pretreatment was performed for $1 \mathrm{~h}$.

\section{Permeation in vitro}

After skin pretreatment, the donor compartment was filled in with $3 \mathrm{~mL}$ solution of domperidone $(0.5 \mathrm{~g} / \mathrm{L}$ in the citric buffer $\mathrm{pH} 5$ and $4 \mathrm{~g} / \mathrm{L}$ in $0.1 \mathrm{M} \mathrm{HCl} \mathrm{pH} \mathrm{1)} \mathrm{while} \mathrm{the}$ receptor compartment was filled in with PBS at a $\mathrm{pH}$ of 6.8. The permeation was done for $8 \mathrm{~h}$. A total of $2 \mathrm{~mL}$ samples were collected from the receptor compartment and immediately replaced with PBS at a pH of 6.8 in the same volume. Sample concentrations were determined by UV spectrophotometer at a wavelength of $285 \mathrm{~nm}$.

\section{Data analysis}

The cumulative permeation of domperidone was calculated. Then, the data were analyzed using WinSAAM (Windows-based Simulation Analysis and Modelling-WinSAAM Project Group, University of Pennsylvania). The evaluation of an appropriate compartmental model of transport was analyzed based on 1) the goodness of fit (GOF) analysis based on the correlation of QO (observed transport) versus QC (calculated/predicted transport) of domperidone (Nugroho et al., 2014) and 2) the corrected Akaike's information criterion (AICc) (Motulsky and Christopoulus, 2003).

\section{RESULTS AND DISCUSSION}

\section{A compartmental model of domperidone transdermal transport}

The in vitro permeation profiles of domperidone across the shed snakeskin (Figure 1). The cumulative amount of transported domperidone was analyzed based on a similar approach reported by Nugroho et al. in losartan transport (Nugroho et al., 2014). We proposed a three- and four-compartments model involving a lag compartment (Figure 2). 


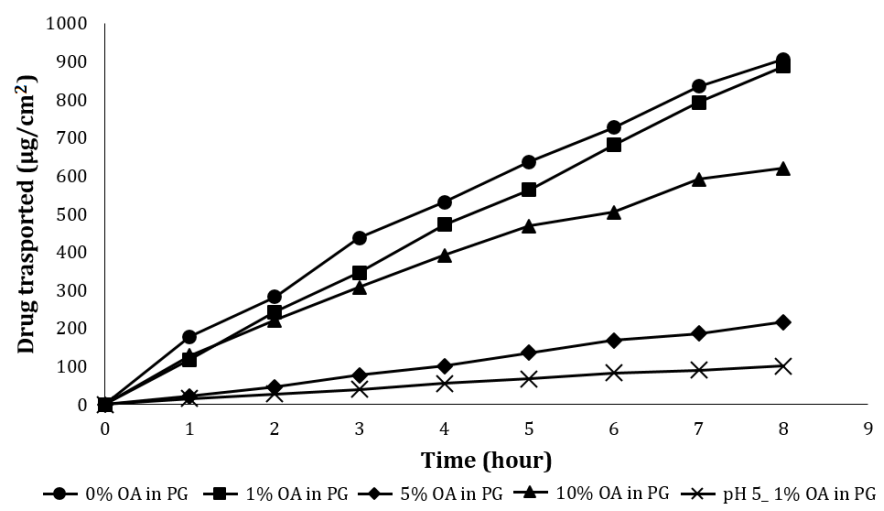

Figure 1. Permeation profiles of domperidone using 1\% OA (oleic acid) in PG (propylene glycol) for pH 5 $(n=3)$ and different concentrations of $\mathrm{OA}$ in $\mathrm{PG}$ for $\mathrm{pH} 1(\mathrm{n}=4)$.
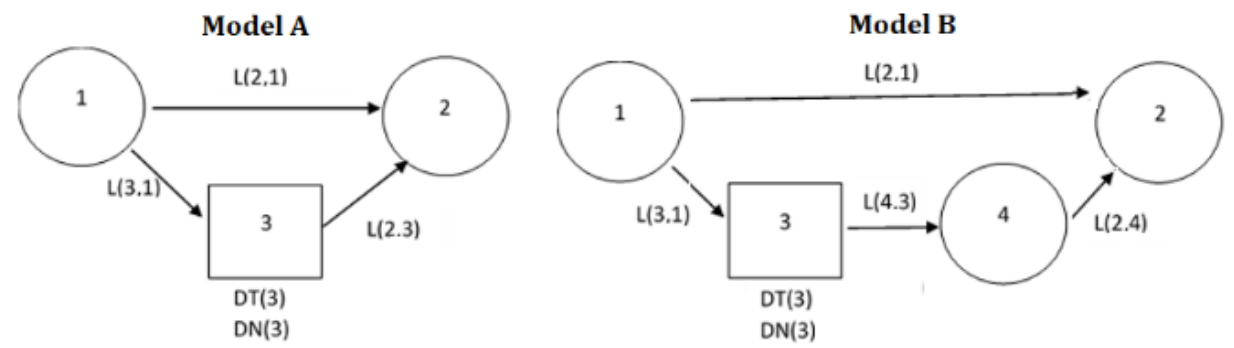

Figure 2. Schematic proposed models for transdermal transport of domperidone.

Table I. AICc Parameters of proposed model A and B

\begin{tabular}{cccc}
\hline Condition & Replicate & Model A & Model B \\
\hline a1\% OA in PG & 1 & 58.83 & 58.66 \\
& 2 & 49.20 & 49.31 \\
& 3 & 23.38 & $2.60^{*}$ \\
b0A 0\% in PG (Control) & 1 & 35.05 & $28.12^{*}$ \\
& 2 & 43.94 & 43.57 \\
& 3 & 62.86 & 47.91 \\
b1\% OA in PG & 4 & 75.19 & 75.93 \\
& 1 & 55.97 & 52.99 \\
& 2 & 60.46 & 60.69 \\
b5\% OA in PG & 3 & 33.98 & $14.12^{*}$ \\
& 4 & 48.24 & 49.12 \\
& 1 & 35.20 & $13.56^{*}$ \\
b10\% OA in PG & 2 & 51.29 & 48.95 \\
& 3 & 38.38 & 45.90 \\
& 4 & 24.31 & 27.16 \\
& 1 & 62.17 & 58.24 \\
& 2 & 66.94 & 73.23 \\
& 3 & 40.57 & 36.72 \\
\hline
\end{tabular}

*The lowest AICc values among data each group a $\mathrm{pH}$ of $5 \pm 0.05$; ${ }^{\mathrm{b}} \mathrm{pH}$ of $1 \pm 0.05$ 

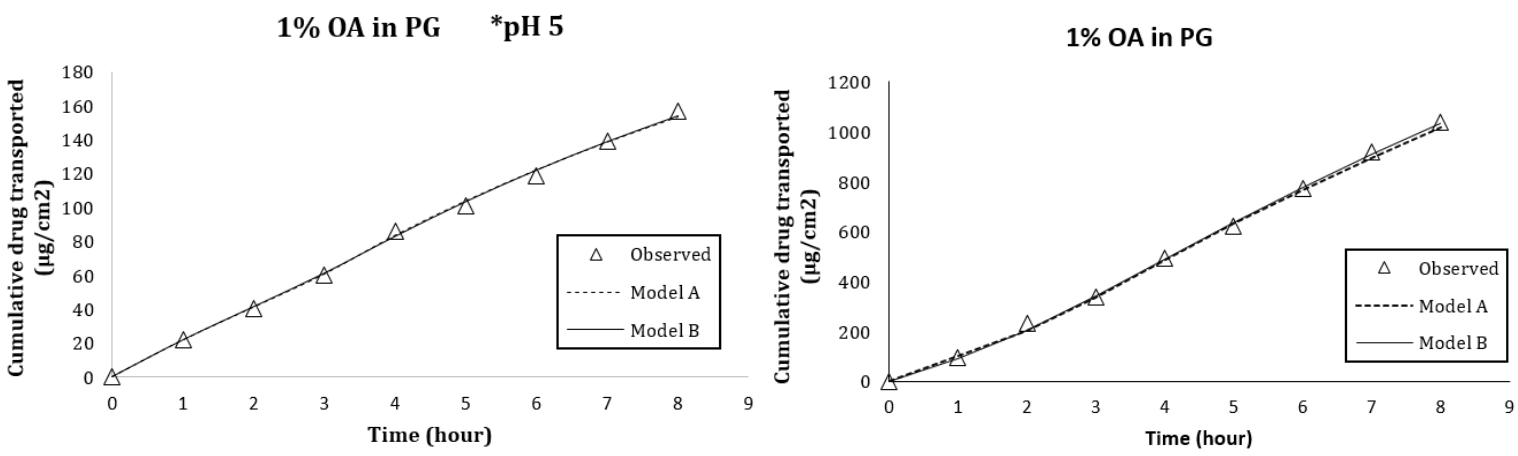

Figure 3. Typical example of fitting data of domperidone using 1\% OA (oleic acid) in PG (propylene glycol) using Model A (---) and Model B (-) for pH of 5 and $\mathrm{pH}$ of 1.
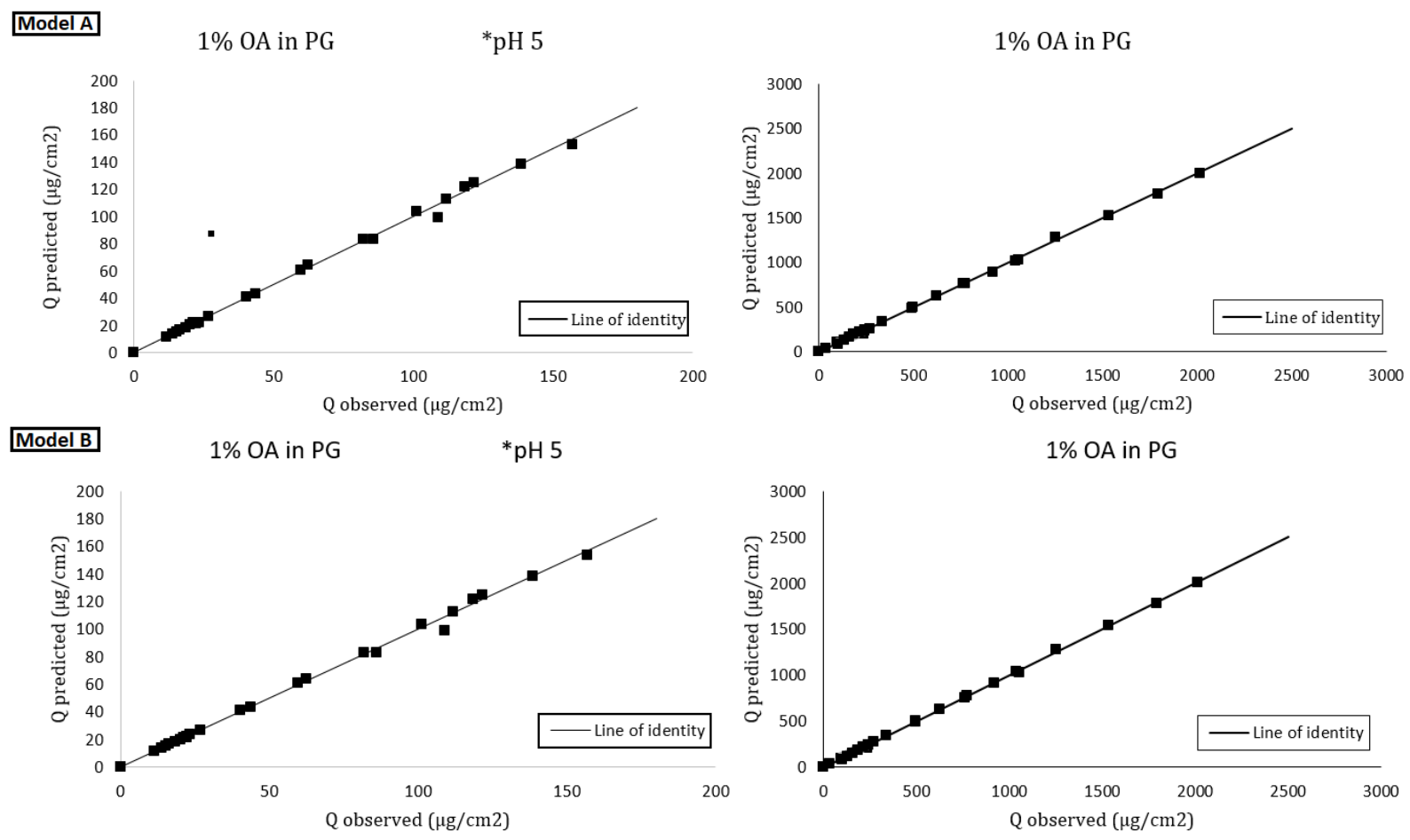

Figure 4. Goodness of fit (GOF) of transdermal transport of domperidone using 1\% OA (oleic acid) in PG (propylene glycol) for $\mathrm{pH}$ of $5\left(^{*}\right)$ and $\mathrm{pH}$ of 1 . The graph shown based on $\mathrm{Q}$ observed tranport versus $\mathrm{Q}$ predicted transport of domperidone; $\mathrm{OA}=$ oleic acid, $\mathrm{PG}=$ propylen glycol. The data were presented from the results of three replicates $\left({ }^{*}\right)$ and four replicates experiments.

The typical examples of the analysis are presentation of model fitting (Figure 3) and based on the goodness of fit (Figure 4).

Data presentation of model fitting (Figure 3) shows model B could fit better than model A. It is also supported by GOF evaluation (Figure 4), which indicated that there was less deviation between observed and software prediction data. Further evaluation was conducted to ensure the best model.
AICc calculation was performed (Table I). The lowest AICc value is preferred because it indicates that the model fits the observed data better than the other models. AICc analysis showed that the appropriate model for domperidone transport is Model B.

Model B is a four-compartmental model involving a lag compartment. The first compartment was the drug in solution. 


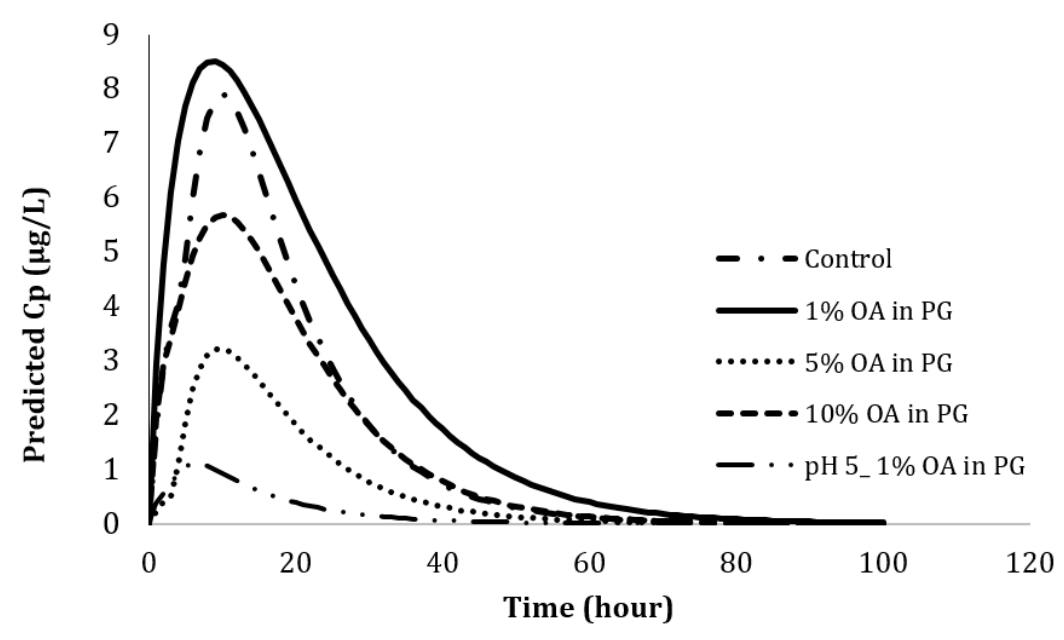

Figure 5. Predicted transport domperidone profiles in vivo by WinsAAM.

Table II. Parameters of transdermal transport in vitro of domperidone analyzed by WinSAAM

\begin{tabular}{cccccc}
\hline & a OA 1 \% in PG & $\begin{array}{c}\text { b OA 0\% in PG } \\
\text { (Control) }\end{array}$ & bOA 1\% in PG & bOA 5\% in PG & b OA 10\% in PG \\
\hline $\mathbf{L ( 2 , 1 )}$ & $0.288(0.210)$ & $0.146(0.021)$ & $0.176(0.124)$ & $0.047(0.015)$ & $0.208(0.056)$ \\
$\mathbf{L ( 3 , 1 )}$ & $0.190(0.142)$ & $0.173(0.089)$ & $0.234(0.084)$ & $0.207(0.104)$ & $0.319(0.166)$ \\
$\mathbf{L ( 2 , 4 )}$ & $1.279(0.944)$ & $0.560(0.237)$ & $0.095(0.032)$ & $1.401(1.301)$ & $0.166(0.071)$ \\
DT(3) & $2.178(0.108)$ & $3.640(0.673)$ & $1.055(0.321)$ & $2.923(1.829)$ & $2.525(0.577)$ \\
$\mathbf{P ( 2 )}$ & $173.12(78.56)$ & $1490.13(496.52)$ & $2118.08(1117.64)$ & $586.62(135.83)$ & $1263.95(780.92)$ \\
\hline
\end{tabular}

a $\mathrm{pH}$ of $5 \pm 0.05$, b $\mathrm{pH}$ of $1 \pm 0.05$. Data represented as mean(SE);(n=3, pH of $5 \pm 0.05 ; n=4, p H 1 \pm 0.05)$.

The second was the receptor compartment. Meanwhile, the third compartment is the lag compartment, and the fourth compartment is the inner part of the skin. The compartmental scheme model indicates that the drug flows into two routes, the first is by directly flowing into the receptor phase, and the other is via transit before reaching the receptor phase.

A chemical enhancer used for these studies is oleic acid in propylene glycol. It had been reported that $\mathrm{OA}$ in $\mathrm{PG}$ could perturb stratum corneum lipids, allowing the drug molecules to pass across the upper layer of skin more easily (Haque and Talukder, 2018) and reach the receptor phase directly (compartment 2). Meanwhile, these are some explanations indicating that the lag compartment (the compartment-3) was present in the model. Based on the Pubchem Database, $\log \mathrm{P}$ of domperidone is 3.9 (National Center for Biotechnology Information, 2019). Lipophilicity of domperidone could make the drug retained before passing into the receptor compartment. It may have the preference to stay longer in hydrophobic parts of the stratum corneum.
Moreover, domperidone is present in 2 forms, unionized and ionized forms. The reports said that the $\mathrm{pH}$ value of the skin was about 4.1-5.8 (Proksch, 2018), and pKa of domperidone was 7.9 (National Center for Biotechnology Information, 2019). Thus, based on the Handerson Hasselbach equation, the ratio of unionized domperidone to the ionized form will be approximately 1:99. In the unionized form, domperidone will be easier to permeate the skin and directly affect the receptor phase. Meanwhile, in the ionized form, as the dominant form, domperidone will be difficult to pass the skin's stratum corneum. This analysis supports explanations on the presence of the lag compartment. After passing the lag compartment, the ionized form of domperidone should be easier to diffuse into the inner skin (compartment 4), which consists of viable and hydrophilic cells.

Based on this modeling approach, parameters were obtained (Table II). The use of $1 \% \mathrm{OA}$ in $\mathrm{PG}$ on $\mathrm{pH} 5$ resulted in the lowest domperidone transport. In contrast, the use of $1 \%$ $\mathrm{OA}$ in $\mathrm{PG}$ on $\mathrm{pH} 1$ provided the highest drug transport. Domperidone is a weak base drug that is 
less soluble in water. The solubility of domperidone also decreases in higher $\mathrm{pH}$. The transport data suggested that the donor concentration of domperidone influenced the permeation. Passive diffusion is driven by a concentration gradient (Nugroho et al., 2004). As the concentration gradient across the skin increased, the percutaneous drug transport also increased. Pranitha and Lakshmi (2018) reported that pH influenced the permeation of drugs. Sildenafil citrate, another weak base drug, was reported to have a higher flux in acidic $\mathrm{pH}(1,2)$ than at the higher $\mathrm{pH}$ levels (4-8) due to the solubility level (Pranitha and Lakshmi, 2018).

The concentration of $\mathrm{OA}$ in $\mathrm{PG}$ also influenced the permeation of the domperidone solution in $\mathrm{pH} 1$. The results in Table 2 indicate that $\mathrm{OA}$ in $\mathrm{PG}$ facilitated stratum corneum perturbation, resulting in a higher transport than the condition without enhancer (control formulation) (Table II). However, an increase in OA - PG concentration decreased domperidone transport even lower than the control formulation. The dominant ionized form of domperidone in this low $\mathrm{pH}$ could be the reason for this phenomenon. The presence of $\mathrm{OA}$ in PG could hinder the drug partition across the skin. Similarly, oleic acid was also reported to reduce the permeability of piroxicam in the nano-emulgel formulation (Aggarwal et al., 2014).

Interestingly, domperidone permeation was appropriately described with the same compartmental model at a $\mathrm{pH}$ of 1 and 5 , i.e. a fourcompartmental model with a lag compartment. The compartmental modeling approach can simulate the steady-state concentration of the drug in plasma based on the estimated in vitro model transport parameters. By using the previously published pharmacokinetic data of domperidone (i.e. $\mathrm{Vd}=399 \mathrm{~L}$ and the elimination half-life $=7.5 \mathrm{~h}$ ) (Helmy and El Bedaiwy, 2014), and the patch with a size of $2 \times 2 \mathrm{~cm}$, the concentrations of drug in plasma (Figure 5). The results indicate the presence of $1 \%$ oleic acid in propylene glycol might facilitate domperidone transport to reach a plasma concentration of approximately $8.5 \mathrm{mg} / \mathrm{mL}$.

\section{CONCLUSION}

A four-compartmental model involving a lag compartment was the suitable model for transdermal transport domperidone in $\mathrm{pH} 5$ and $\mathrm{pH} 1$. The maximum domperidone transport was achieved with a solution at a $\mathrm{pH}$ of 1 in the presence of $1 \% \mathrm{OA}$ in $\mathrm{PG}$ as the chemical enhancer.

\section{ACKNOWLEDGMENT}

The research was financially supported by The Ministry of Research, Technology, and Higher Education (KEMENRISTEK-DIKTI) of Indonesia through Pendidikan Menuju Sarjana Unggul (PMDSU) scheme.

\section{REFERENCES}

Aggarwal, G., Dhawan, B., Harikumar, S., 2014. Enhanced transdermal permeability of piroxicam through novel nanoemulgel formulation. Int J Pharma Investig 4, 65-76. https://doi.org/10.4103/2230973X.133053

Boyce, M.J., Baisley, K.J., Warrington, S.J., 2012. Pharmacokinetic interaction between domperidone and ketoconazole leads to QT prolongation in healthy volunteers: a randomized, placebo-controlled, doubleblind, crossover study: QT study of domperidone and ketoconazole. British Journal of Clinical Pharmacology 73, 411421. https://doi.org/10.1111/j.13652125.2011.04093.x

Haq, A., Michniak-Kohn, B., 2018. Effects of solvents and penetration enhancers on transdermal delivery of thymoquinone: permeability and skin deposition study. Drug Delivery 25, 1943-1949.

https://doi.org/10.1080/10717544.2018.1 523256

Haque, T., Talukder, M.M.U., 2018. Chemical Enhancer: A Simplistic Way to Modulate Barrier Function of the Stratum Corneum. Advanced Pharmaceutical Bulletin 8,169-179. https://doi.org/10.15171/apb.2018.021

Helmy, SA, El Bedaiwy, H.M., 2014. Pharmacokinetics and comparative bioavailability of domperidone suspension and tablet formulations in healthy adult subjects. Clinical Pharmacology in Drug Development 3, 126-131. https://doi.org/10.1002/cpdd.43

Hendriati, L., Nugroho, A.K., 2009. Pengaruh campuran asam oleat-propilen glikol dan iontoforesis terhadap transpor transdermal propranolol. Majalah Farmasi Indonesia 20, 217-223.

Khanday, M.A., Rafiq, A., Nazir, K., 2017. Mathematical models for drug diffusion through the compartments of blood and tissue medium. Alexandria Journal of Medicine 53, 245-249. 
https://doi.org/10.1016/j.ajme.2016.03.00 5

Motulsky, H.J., Christopoulus, A., 2003. Fitting models to biological data using linear and nonlinear regression. A practical guide to curve fitting. GraphPad Software, Inc. San Diego CA.

National Center for Biotechnology Information, 2019. Domperidone [WWW Document]. URL https://pubchem.ncbi.nlm.nih.gov/compou nd/3151 (accessed 8.30.19).

Nugroho, A.K., Binnarjo, A., Hakim, A.H., Ermawati, Y., 2014. Compartmental Modeling Approach of Losartan Transdermal Transport in vitro. Indonesian Journal of Pharmacy 25, 31-38. https://doi.org/10.14499/indonesianjphar m25iss1pp31-38

Nugroho, A.K., Della Pasqua, O., Danhof, M., Bouwstra, J.A., 2004. Compartmental Modeling of Transdermal Iontophoretic Transport: I. In vitro Model Derivation and Application. Pharmaceutical Research 21, 1974-1984.

https://doi.org/10.1023/B:PHAM.0000048 187.54125.ac

Nugroho, A.K., Della-Pasqua, O., Danhof, M., Bouwstra, J.A., 2005. Compartmental modeling of transdermal iontophoretic transport II: In vivo model derivation and application. Pharmaceutical Research 22, 335-346. https://doi.org/10.1007/s11095004-1870-2
Pattnaik, S., Swain, K., Bindhani, A., Mallick, S., 2011. Influence of chemical permeation enhancers on transdermal permeation of alfuzosin: an investigation using response surface modeling. Drug Development and Industrial Pharmacy 37, 465-474. https://doi.org/10.3109/03639045.2010.5 22192

Pranitha, A., Lakshmi, P.K., 2018. Effect of pH on weakly acidic and basic model drugs and determination of their ex vivo transdermal permeation routes. Braz. J. Pharm. Sci. 54, 1$8 . \quad$ https://doi.org/10.1590/s217597902018000200070

Proksch, E., 2018. pH in nature, humans and skin. The Journal of Dermatology 45, 1044-1052. https://doi.org/10.1111/1346-8138.14489

Sarath, C., Vipin, K., Augusthy, A.R., Shahin, M., Sabna, N.S., 2014. Effectiveness of Sodium CMC as a Polymer for the Development of Transdermal Patches Containing Paracetamol IP in Paediatric Category. British Biomedical Bulletin 2, 174-186.

Stefanovski, D., Moate, P.J., Boston, R.C., 2003. WinSAAM: $\quad \mathrm{A}$ windows-based compartmental modeling system. Metabolism: Clinical and Experimental 52, 1153-1166. https://doi.org/10.1016/S00260495(03)00144-6 